\title{
ANALYSIS OF DIALOGUE TECHNIQUE ACCEPTANCE OF DIAGNOSIS BASED CLINICAL DECISION SUPPORT SYSTEM
}

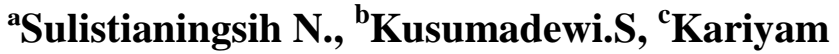 \\ ${ }^{\mathrm{a}, \mathrm{b}}$ Master of Informatics Engineering, Faculty of Industry Technology, Islamic University of \\ Indonesia \\ ${ }^{\mathrm{c}}$ Department of Statistics, Faculty of Mathematics and Science, Islamic University of Indonesia \\ E-Mail: neny.sulistia@gmail.com
}

\begin{abstract}
Many decision support systems have been developed to diagnose diseases, but in reality many of these systems fail when applied. This is mainly due to the difficulties in the use of the system due to incompatibility between the system interface and the wishes of physicians. The purpose of this study was to determine the interface design of decision support systems for diseases diagnose in accordance with physician's wishes and to determine the effects of perceived usefulness and perceived ease of use on the behavioral intention to use the interface design. The data analysis technique used included the Wilcoxon test, the Friedman test, a principal component analysis and a multiple linear regression analysis. From the data analysis it was found that in anamneses and physical examinations, respondents prefer the interface design of natural language processing and a form filling dialogue, whereas in supported examinations, respondents prefer windowing system interface designs. Advanced data analyses found an influence of the variables of perceived usefulness and perceived ease of use on the behavioral intention to use and this influence has a positive effect.
\end{abstract}

Keywords: Decision Support System to Diagnose Disease, Anamneses, Physical Examination, Supported Examination. 


\section{INTRODUCTION}

Research that combines informatics and medical science has been conducted for years. The goal is to incorporate technology in the field of informatics and medical science to simplify and streamline medical practices to help more people. One example of this research field is the use of decision support systems to diagnose diseases.

To acheive this objective, much research and system development were conducted to create a decision support system to help physicians to diagnose diseases. However, in fact, many failures happened during system implementation. One failure was mainly due to the difficulties in the use of the system due to the incompatibility between the system interface and the wishes of physicians [1] [2] [3] [4] [5]. Later, this failure created some new problems such as; longer times needed to learn the new system, low system productivity, and increased human error in the system [6]. These problems led physicians to prefer the use of manual methods by relying on knowledge and experience to diagnose patient.

The reason for the incompatibility between the system interface and the wishes a physician is due to research related to interface design not being carried out before system development according to the wishes of the physicians as users of the system [7]. To answer this question, several studies have been conducted. One of them was done by Sulistianingsih [7]. However, this study only discusses the stage of anamneses of diseases diagnosis. While the physical examination and supported examination has not been discussed. Thus, the purpose of this study was to determine the interface design of decision support systems to diagnose disease in accordance with the wishes of physicians not only in anamesis but also in physical and supported examination. In this study not only discussed the results of previous studies on anamesis but also discusses the results of a physical examination and investigation. In addition, this study also conducted an analysis to determine the effects of perceived usefulness and perceived ease of use on the behavioral intention to use in the interface design. Location data collection was done in the special province of Yogyakarta.

\section{THEORY}

\section{Decision Support System to Diagnosing Disease}

Decision Support Systems (DSS) is an interactive computer-based system and aims to assist users in the selection of assessment activities and decision [8]. DSS does not replace humans, but helps people in solving complex problems with the integration of the various sources of information, providing access to knowledge relevant intelligence and assist in the process of structuring and optimizing decision. DSS for diagnosing disease developed based on the comprehension that the physician to diagnose the patient's illness limited by cognitive problems and the complexity of the health issues that must be resolved. Doctor cognitive problems associated with the difficulties of doctors as an individual to perform activities of multi-tasking, memory capacity and other external issues that could affect the outcome of the patient's diagnosis. Meanwhile, the complexity of health problems influenced by the number of people who increasingly numerous and continuous progression of the disease occurs, thus allowing the emergence of a variety of health problems that are not contained in the knowledge and experience of physicians in diagnosing the disease. These problems can cause errors physicians in diagnosing a patient's illness.

DSS to diagnosing disease consists of two components, namely health knowledge base and interfaces [9]. Health knowledge base consists of a list of symptoms and diseases, and the relationship between the symptoms and the disease, while the input interface describes the information that can be matched with the patient's health knowledge base to get a decision. Components of the DSS for diagnosing disease can be seen in Figure 1.

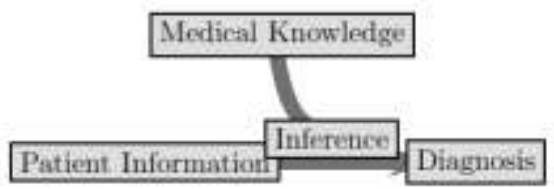

Figure 1. Component of DSS for diagnosing disease [9] 


\section{Dialogue Style}

Dialogue style is the various types of dialogue techniques in computer that can allow the interaction between computers and humans as computer users [10]. According to Santosa [10], categorization of dialogue style are as follows:

1. Command line dialogue.

2. Programming language dialogue.

3. Natural language dialogue.

4. Menu system .

5. Form filling dialogue.

6. Icon-based interface.

7. Windowing system.

8. Direct manipulation.

9. Interaction-based graphical interface.

In this study, dialogue style that is displayed on the questionnaire has been chosen selectively. This is partly because the respondent is a doctor's educational background was not from study program of informatics engineering or short of, then several dialogue style that are too technical is not included in the questionnaire in this study, such as command line dialogue and programming language dialogue. In addition, because the anamneses and physical examination were restricted to only interface design of input information and supported examination only to interface design of output, the selection of dialogue style in questionnaire are also tailored to meet the constraints of this problem. Another reason of selectivity in choosing dialogue style that is displayed on the questionnaire is because when filling out the questionnaire by respondents to be utilized as effectively as possible due to the tight schedule of patients examination by doctors. So, in this study only used five dialogue style in interface design, namely in stage of anamneses and physical examination dialogue style used are natural language processing, menu system and form filling dialogue and in stage of supported examination are windowing system and interaction-based graphical interface.

\section{Technology Acceptance Model}

In this study, statistical analyzes were performed to determine the interface design of decision support systems to diagnose disease in accordance with the wishes of physicians at each stage of disease diagnosis. Advanced data analysis performed to determine the influence of variable of perceived usefulness and perceived ease of use. On further analysis, the theory used is development of Technology Acceptance Model (TAM). TAM is used to predict acceptance by the user of computer [11]. Besides that, TAM is also used to test the reasons for user refusal in using the system and the influence of the system design to user acceptance. TAM models developed by Davis [12] can be seen in Figure 1.

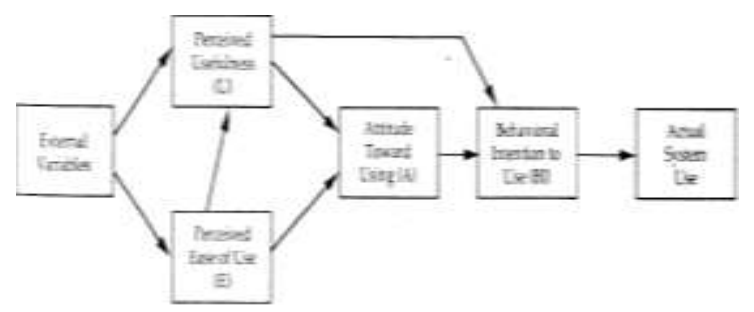

Figure 2. Model of Technology Acceptance Model [12]

After the TAM model development undertaken by Davis et.al [13], many models of improvements made by other researchers using the basic model of TAM. Such as TAM improvement conducted by Chang [14], which removes the relationship of perceived usefulness and perceived ease of use. Other TAM improved model is a model studied by Ramayah [15]. On the improved model, the external variable is replaced by a system interface design. Other differences between models TAM improvement by Ramayah [15] and TAM models by Davis [12] is construct of the attitude toward using was eliminated. According Ramayah [15], it was based on research by Davis [13] that there is a stronger relationship and consistent with the perception of use in comparison with other variables. Ramayah [15] also refers to research by [16] that individuals are more likely to use technology that feels comfortable, useful and socially desirable although not enjoy using technology that made possible the existence of a direct relationship between beliefs and intentions.

Several studies with improvements of TAM model as practiced by Agarwal [17] , Liu [18] and Serenko [19] has eliminated not only the 
variables of attitude toward using but also actual system use. According Serenko [19], all previous studies have identified a strong relationship between the actual system use and behavioral intention to use, so that only measure variable behavioral intention to use would meet the objectives of the model.

In this study, survey respondents still a design and there is no real system that can be tested for acceptance. So that the TAM model used in this study is shown in Figure 3.

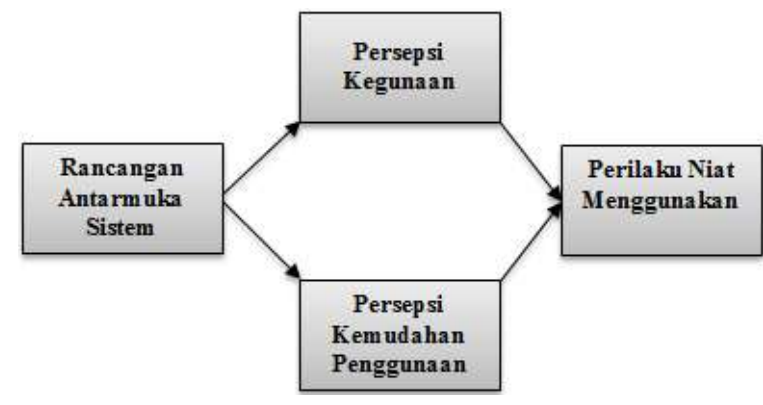

Figure 3. Model of TAM in this Study

\section{METHOD}

\section{Material}

In this study there is a proposed interface design in each diagnosis stage. For the stage of anamneses, the proposed interface designs are natural language processing, form filling dialogue and the menu system. The same interface design will also be presented at the physical examination stage. Differences in the interface designs of both stages are located within the input data information of both stages. The input data information was used in this research is referring to [20] As for the supported examination interface design, it will be proposed as a windowing system and interaction-based graphical interface.

In addition to the interface design for each stage of diagnosis, a questionnaire was also given to the respondents to answer for the purposes of this research. This questionnaire incorporated a 7 point Likert scale $(1=$ strongly disagree and $7=$ strongly agree), in according to research by Venkatesh [21]. Before completing the questionnaire, a data flow simulation of teh system interface design at each stage of diagnosis will be explained to the respondents. Indicators of each variable used in this study can be seen in Sulistianingsih [7].

Respondents in this study are physicians on duty at each general hospital in the special province of Yogyakarta. General hospitals that participated in this study include the General Hospital of Wates, Kulon Progo, the General Hospital of Wonosari, Gunung Kidul and the General Hospital of Panembahan Senopati, Bantul. Moreover, because there are two general hospitals in the Sleman district namely General Hospital of Sleman and General Hospital of Prambanan, both are included in this study so that the total number of general hospitals that participated in this study was five.

\section{Data Analysis}

The data analysis techniques used in this study are the Friedman test and Wilcoxon test which were used to determine the system interface design with the wishes of physicians. Based on the results of the data analysis, a multiple linear regression analysis was performed to determine the influence of perceived usefulness and perceived ease of use on the behavioral intention to use this interface design. Before the multiple linear regression analysis was performed, a principal component analysis was conducted to reduce the dimensionality of the items reklated to the variables of perceived usefulness, perceived ease of use and behavioral intention to use.

\section{RESULT AND DISCUSSION}

The number of respondent in this study were 55 respondents, with the number of female respondents being 37 respondents $(67 \%)$ and the number of male respondents were 18 respondents $(33 \%)$. The mean age of the respondents was 26.78 years and the mean length of work of the respondents was 4.88 years. Confident interval used in this study was $85 \%$ (value of $\alpha=.25$ ) The type of physicians who responded to this study were entirely general physician. General physicians in this study were physicians on duty in the emergency unit and a few of them in the ward unit. This is because most general physician in hospitals work in the emergency unit, while only a few general physicians work in the ward unit. 
From questionnaires distributed to respondents showed that at stage of anamneses as many as 20 respondents are agree (judging by points of 6) and 2 respondents are strongly agree (judging by points of 7) for the design of natural language processing interface, as many as 11 respondents are agree and 1 respondent are strongly agree on the interface design of menu system , and as many as 14 respondents are agree and 6 respodents are strongly agree to interface design of form-filling dialogue. Results of the questionnaire on stage of anamneses can be seen in Figure 4.

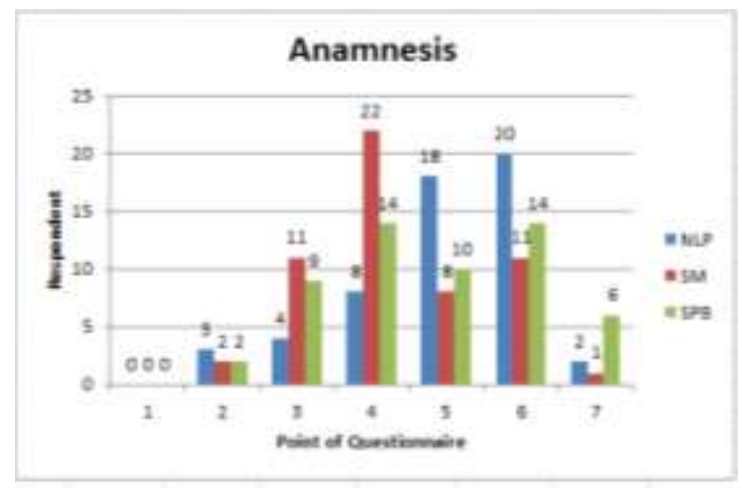

Figure 4. Result of questionnaire in stage of anamneses

Where as at the physical examination stage as many as 25 respondents are agree and 4 respondents are strongly agree to the interface design of natural language processing, as many as 11 respondents are agree and 3 respondent are strongly agree to the interface design of menu system, and as many as 17 people are agree and 6 respondents are strongly agree for form-filling dialogue. Results of the questionnaire on physical examination stage can be seen in Figure 5.

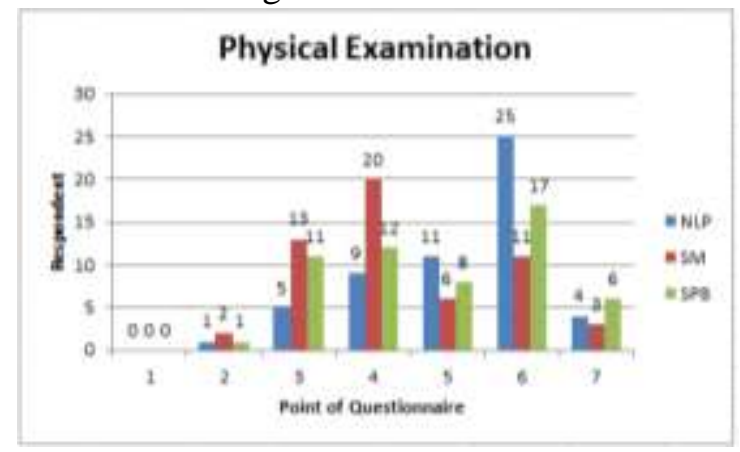

Figure 5. Result of questionnaire on physical examination stage
At supported examination stage as much as 23 respondents are agree and 7 respondents are strongly agree to interface design of windowing system and 17 respondents are agree and 5 respondents are strongly agree to interactionbased graphical interface. Results of the questionnaire on supported examination stage can be seen in Figure 6.

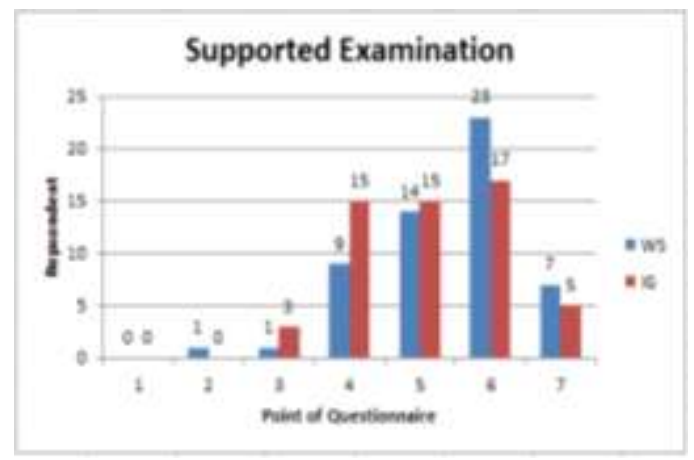

Figure 6. Result of questionnaire on supported examination stage

Statistical analysis to determine the interface design according to the user's wishes conducted at each stage of disease diagnosis by adjusting the respective proposed interface design.

\section{Stage of Anamneses}

As in the results of research conducted by Sulistianingsih [7] note that from the Friedman test conducted was found Asymp. Sig value was .025 and from this value, it can be concluded that there is at least one interface design that is better suited to the wishes of physicians compared with at least one other interface design at the stage of anamneses.

Furthermore, from Wilcoxon test results conducted to determine the appropriate interface design based on user's wishes at stage of anamneses it was known that The Asymp. Sig value resulting from Wilcoxon test for the combination of natural language processing and menu system was .001 and .560 for combination of natural language processing and form-filling dialogue, and .024 for combination of the menu system and form-filling dialogue. From the Asymp. Sig value of each pair combinations, it can be concluded that only the combination of natural language processing and form-filling dialogue has the same distribution as Asymp. Sig value of this pair combination > 
value of $\alpha$. It shows natural language processing and form-filling dialogue in accordance with the wishes of physicians. Therefore, advanced analysis will be performed on both the interface design to determine the effect of the variable of perceived usefulness and perceived ease of use on the variable of behavioral intention to use.

\section{Natural language processing}

From advanced analysis conducted by Sulistianingsih, Kusumadewi, and Kariyam (2014) on the stage of anamneses using principal components analysis found eigenvalue of the variables of perceived usefulness, perceived ease of use and behavioral intention to use is greater than 1 (eigenvalues of $X_{1}=3.802, X_{2}=2.648$ and $Y=$ 1.971), and the value of each variable is represented simply by one component. Furthermore, a multiple linear regression analysis found that there is at least one variable between perceived usefulness $\left(X_{I}\right)$ and perceived ease of use $\left(X_{2}\right)$ that influences the behavioral intention to use $(Y)\left(F_{\text {count }}=89.710\right.$, $\left.F_{\text {table }}=1.9680, F_{\text {count }}>F_{\text {table }}\right)$ with a significance value of .000 .

In addition, other results obtained from the multiple regression analysis that the value of the model parameters for the variable perceived usefulness $\left(\beta_{1}\right)$ is positive $(+.262)$ and for the variable perceived ease of use $\left(\beta_{2}\right)$ is also positive $(+.405)$, therefore it can be concluded that the higher the value of the each variable, the higher the value of variable of behavioral intention to use.

\section{Form-filling dialogue}

Advanced data analysis for the interface design is also performed to determine the influence of variable of perceived usefulness and perceived ease of use. Principal component analysis conducted previously found that eigenvalue of the variables of perceived usefulness, perceived ease of use and behavioral intention to use is greater than 1 (eigenvalues of $X_{1}=4.807, X_{2}=3.872$ and $Y=$ 2.983 ), and the value of each variable is represented simply by one component. Furthermore, a multiple linear regression analysis found that the $F_{\text {count }}$ was 117.501 (Sig. $\left.F=.000, F_{\text {table }}=1.9680\right)$. As the value of $F_{\text {count }}$
$>\mathrm{F}_{\text {table }}$, it can be concluded there is at least one variable between perceived usefulness $\left(X_{1}\right)$ and perceived ease of use $\left(X_{2}\right)$ that influences the behavioral intention to use $(Y)$ with a significance value of .000 .

In addition, from the multiple regression analysis found that the value of the model parameters for the variable perceived usefulness $\left(\beta_{1}\right)$ is positive $(+.290)$ and for the variable perceived ease of use $\left(\beta_{2}\right)$ is also positive $(+.337)$. Therefore it can be concluded that the higher the value of each variables, the higher the value of variable behavioral intention to use.

\section{Stage of Physical Examination}

For stage of physical examination, the same data analysis performed on each interface design (natural language processing, the menu system and dialog-based charging accreditation forms). From the Friedman test conducted on the three interface designs, it was found that mean rank-1 of the design interface is a natural language processing (mean $=5.2000, S D=$ 1.19257 , mean rank $=2.28$ ), followed by formfilling dialogue $($ mean $=4.8545, S D=1.39335$, mean rank $=2.01)$, and menu system $($ mean $=$ 4.3636, $S D=1.29620$, mean rank = 1.71). In addition, it also obtained the Asymp. Sig value, which was .025 and from this value, it can be concluded that there is at least one interface design that is better suited to the wishes of physicians compared with at least one other interface design at stage of physical examination.

Furthermore, after the Friedman test, the Wilcoxon test was performed to determine the interface design appropriate to the with physicians wishes. From Wilcoxon test was found Asymp. Sig value for the combination of natural language processing and menu system is .000 , and it is .214 for natural language processing and form-filling dialogue, and .017 for the menu system and form-filling dialogue. From the Asymp. Sig value of each pair combinations, it can be concluded that only the combination of natural language processing and form-filling dialogue has the same distribution as Asymp. Sig value of this pair combination > value of $\alpha$. It shows natural language processing and form-filling dialogue in accordance with the wishes of physicians. Therefore, for advanced analysis to both 
interface design will conducted to tested effect of the variable of perceived usefulness and perceived ease of use on the variable behavioral intention to use on each interface design on stage of physical examination.

\section{Natural language processing}

To conducted advanced analysis like in stage of anamneses, principal components analysis conducted first and from it was found eigenvalue of the variables of perceived usefulness, perceived ease of use and behavioral intention to use is greater than 1 (eigenvalues of $X_{1}=4.717, X_{2}=3.865$ and $Y=$ 2.975 ), and the value of each variable is represented simply by one component.

Furthermore, a multiple linear regression analysis found that the $F_{\text {count }}$ was 60.657 and $F_{\text {table }}$ was 1.9680 . As the value of $F_{\text {count }}>F_{\text {table }}$, it can be concluded there is at least one variable between perceived usefulness $\left(X_{I}\right)$ and perceived ease of use $\left(X_{2}\right)$ that influences the behavioral intention to use $(Y)$ with a significance value of .000 .

In addition, other results obtained from the multiple regression analysis include the value of each variable coefficient $(\beta)$, so that the regression equation formed is

$$
Y=0.761+0.280 X_{1}+0.224 X_{2}
$$

From the equation formed for the variable behavioral intention to use $(Y)$, it is determined that the value of the model parameters for the variable perceived usefulness $\left(\beta_{1}\right)$ is positive $(+$ $.280)$ and for the variable perceived ease of use $\left(\beta_{2}\right)$ is also positive $(+.224)$, therefore it can be concluded that the higher the value of each variables, the higher the value of variable behavioral intention to use.

\section{Form-filling dialogue}

A principal components analysis found eigenvalue of the variables of perceived usefulness, perceived ease of use and behavioral intention to use is greater than 1 (eigenvalues of $X_{1}=3.884, X_{2}=3.865$ and $Y=$ 2.983 ), and the value of each variable is represented simply by one component.

Furthermore, a multiple linear regression analysis found that the $F_{\text {count }}$ was 146.778 and $F_{\text {table }}$ was 1.9680 . As the value of $F_{\text {count }}>F_{\text {table }}$, it can be concluded there is at least one variable between perceived usefulness $\left(X_{I}\right)$ and perceived ease of use $\left(X_{2}\right)$ that influences the behavioral intention to use $(Y)$ with a significance value of .000 .

In addition, other results obtained from the multiple regression analysis include the value of each variable coefficient $(\beta)$, so that the regression equation formed is

$$
Y=-0.413+0.294 X_{1}+0.287 X_{2}
$$

From the equation formed for the variable behavioral intention to use $(Y)$, it is determined that the value of the model parameters for the variable perceived usefulness $\left(\beta_{1}\right)$ is positive $(+$ .294) for the variable perceived ease of use $\left(\beta_{2}\right)$ is also positive $(+.287)$, therefore it can be concluded that the higher the value of each variables, the higher the value of variable behavioral intention to use.

\section{Stage of Supported Examination}

The same analysis data step also conducted in supported examination and from the Friedman test conducted on two design interfaces in the supported examination stage, value are obtained for windowing system (mean $=5.5273, S D=1.03377$, mean rank $=$ 1.61) and for the interaction-based graphical interface (mean $=5.1091, S D=1.08308$, mean rank $=1.39$ ). In addition, value of Asymp. Sig was .064 was also obtained. From this value, it can be concluded that there is at least one interface design that is better suited to the wishes of physicians compared to at least one other interface design at stage of supported examination.

Furthermore, Wilcoxon test also conducted in stage of supported examination. As there are only two pairs of interface designs proposed at this stage, the Wilcoxon test is only performed on the pair combination of a windowing system and interaction-based graphical interface. The Asymp. Sig value resulting from the Wilcoxon test of the pair combination of windowing system and interaction-based graphical interface was .051. From the Asymp.Sig value, it can be concluded that the pair combination of a windowing system and interface-based graphical interactions has a different distributions as the Asymp. Sig value < value of $\alpha$. 
To define further the interface design is more in accordance with physician wishes at this stage, as can be seen from the negative rank and positive rank of 27 and 15, respectively, which were obtained from the Wilcoxon test. Negative rank values indicate the number of respondents who prefer a windowing system design to an interactionbased graphical interface while a positive rank value indicates the number of respondents who prefer an interaction-based graphical interface to a windowing system. From the results, it can be concluded that the respondents chose a windowing system interface design at this stage more often than chose an interaction-based graphical interface. Therefore, variables perceived usefulness and perceived ease of use of this design interface will be processed to determine their effects on the variable behavioral intention to use.

Before conducting further analysis using multiple linear regression, principal component analysis should also be carried out as in the previous stage of diagnosing disease and from principal components analysis found that the eigenvalue of the variables of perceived usefulness, perceived ease of use and behavioral intention to use is greater than 1 (eigenvalues of $X_{1}=4.825, X_{2}=3.874$ and $Y=$ 2.962 ), and the value of each variable is represented simply by one component.

Furthermore, a multiple linear regression analysis found that the $F_{\text {count }}$ was 169.109 and $F_{\text {table }}$ was 1.9680 . As the value of $F_{\text {count }}>F_{\text {table }}$, it can be concluded there is at least one variable between perceived usefulness $\left(X_{I}\right)$ and perceived ease of use $\left(X_{2}\right)$ that influences the behavioral intention to use $(Y)$ with a significance value of .000 .

In addition, other results obtained from the multiple regression analysis include the value of each variable coefficient $(\beta)$, so that the regression equation formed is

$$
Y=-0.186+0.224 X_{1}+0.381 X_{2}
$$

From the equation formed for the variable behavioral intention to use $(Y)$, it is determined that the value of the model parameters for the variable perceived usefulness $\left(\beta_{1}\right)$ is positive $(+$ $.224)$ and for the variable perceived ease of use $\left(\beta_{2}\right)$ is also positive $(+.381)$, therefore it can be concluded that the higher the value of each variables, the higher the value of variable behavioral intention to use.

\section{Discussion}

This study was conducted to determine the interface design in accordance with the doctor's wishes for the stages of diagnosis. From the results of statistical analysis performed on questionnaire distributed to physicians found that at the stage of anamneses, respondents chose the interface design of natural language processing and form-filling dialogue. The same thing happened at the stage of physical examination. Whereas at the stage of supported examination, respondents prefer the interface design of windowing system.

From the interviews conducted to respondents, the reason of choosing the interface design of natural language processing in stage of anamneses and physical examination is due to respondents not to be confused to choose the input data so that the time required for the input is not too much and easier. Another reason is if they use the interface design of form-filling dialogue, their concentration will split between communicating with patients and make choices on the computer. This leads to two-way communication between patient and respondents to be disrupted. While respondents who chose form-filling dialogue found because the respondent would be easier to enter data since the data is already available. And for respondents who chose the interface design of windowing system for supported examination stage, their reason is that one patient can have some results of supported examination, so it would be helpful if these results can be freely positioned in accordance with the wishes of the respondent.

Further statistical analysis to determine the effect of the variable of perceived usefulness and perceived ease of use on variable behavior intention to use the interface design is chosen at each stage of disease diagnosis found that at each of the interface design, variable perceived usefulness and perceived ease of use respectively have a positive influence on variable of behavioral intentions to use as evidenced by the value of the model parameters $(\beta)$ in the variable perceived usefulness and 
perceived ease of use that is positive. Positive values of the model parameter mean that the increase in the value of the variable of perceived usefulness will result in the increase in value of the variable behavioral intention to use. The same thing also applies to the relationship between the variable of perceived ease of use and behavioral intention to use.

\section{CONCLUSION}

The conclusion that can be drawn from the data analysis previously conducted is that at the stage of anamneses, respondents prefer to use natural language processing and form-filling dialogue. The same is also true at physical examination stage, while at the supported examination stage, respondents prefer a windowing system.

Moreover, from the data analysis of each design interface at each diagnosis stage, it was found that for each interface design, there are influences of the variables perceived usefulness and perceived ease of use on the variable behavioral intention to use. This influence is comparable, meaning that increasing the value of the variables perceived usefulness and

\section{REFERENCES}

[1] R., \& Jaspers, M. W. Khajouei, CPOE System Design Aspects and Their Qualitative Effect on Usability.: MIE, 2008, pp. 309-314.

[2] R., Metlay, J. P., Cohen, A., Abaluck, B., Localio, A. R., Kimmel, S. E., et al. Koppel,.: American Medical Association, 2005, pp. 1197-1203.

[3] G. O., Cimino, J. J., Hupp, J. A., \& Hoffer, E. P. Barnett, "DXplain An Evolving Diagnostic Desicion-Support System," Journal of the American Medical Association, pp. 68-74, 1987.

[4] P. S., You, J. J., Dhaliiwal, J., Koff, D., Mackay, J. A., Weise-Kelly, L., et al. Roshanov, Can Computerized Clinical Decision Support Systems Improve Practitioner's Diagnostic Test Ordering perceived ease of use will also increase the value of the variable behavioral intention to use.

From these results, in the future in development of decision support systems for diseases diagnose, system developers can use interface of natural language processing combined with form-filling dialogue for stage of anamneses and physical examination. Whereas at the stage of supported examination based on the results of this study are advised to use interface design of windowing system. Moreover, in the development of decision support systems in diseases diagnose, system developers are advised to consider the perceived usefulness and perceived ease of use to increase the user's intention to use the system.

This research is still far from perfect. Mainly related to the respondents who participated in this study. For future research can be done by increasing the number of respondents. In addition, the development of research can also be done by increasing the choices number of interface design that can be selected by the respondents.

Behavior? A Decision-MakerResearcher Partnership Systematic Review.: Implementation Science, 2011, pp. $6: 88,1-12$.

[5] S. T., Han, Y. Y., Carcillo, J. A., Clark, R. S., Watson, R. S., Nguyen, T. C., et al. Venkataraman, Unexpected Increased Mortality After Implementation of $A$ Commercially Sold Computerized Physician Order Entry System.: Pediatrics, 2005.

[6] D. W., Kuperman, G. J., Rittenberg, E., Teich, J. M., Fiskio, J., Ma'luf, N., et al. Bates, "A Randomized Trial of a Computer-based Intervention to Reduce Utilization of Redundant Laboratory Tests," The American Journal of Medicine, pp. 144-150, 1999. 
[7] N., Kusumadewi, S., \& Kariyam. Sulistianingsih, "Analisis Penerimaan Teknik Ragam Dialog Pada Tahap Anamnesa Untuk Penegakan Diagnosa Penyakit Berbasis Sistem Pendukung Keputusan," Seminar Nasional Teknologi Industri dan Informatika, pp. 341-348, 2014.

[8] Medha Kulkarni, Ashish Wadhaval, and Preeyal Shinde, "Decision Support System," International Journal of Engineering Trends and Technology, Vol. 4, pp. 671-674, April 2013.

[9] Kavishwar B. Wagholikar, Vijayraghavan Sundararajan, and Ashok W. Deshpande, "Modelling Paradigms for Medical Diagnostic Decision Support: A Survey and Future Directions," Journal of Medical Systems, Vol. 36, pp. 3029-3049, 2012.

[10] Insap Santosa, Interaksi Manusia dan Komputer: Teori dan Praktek. Yogyakarta: Penerbit Andi, 2004.

[11] J. Bradley, "If We Build It They Will Come? The Technology Acceptance Model.," in Information System Theory Explaining and Predicting Our Digital Society, Vol. 1. New York: Springer, 2012, pp. 19-36.

[12] Fred D. Davis, Richard P. Bagozzi, and Paul R. Warshaw, "User Acceptance of Computer Technologgy: A Comparison of Two Theoretical Models," in Management Science, U.S.A, 1989, pp. 982-1003.

[13] Fred D. Davis, "Perceived Usefulness, Perceived Ease of Use, dan User Acceptance of Information Technology," MIS Quarterly, Vol. 13, No. 3, pp. 319340, September 1989.

[14] Paul Vincent Chang, "The VValidity of an Extended Technology Acceptande Model (TAM) for Predicting Intranet/Portal Usage," North Carolina,
2004.

[15] T Ramayah, Ma'ruf J Jasman , Muhamad Jantan, and Osman Mohamad, "Technology Acceptance Model: Is It Applicable to Users and Non Users of Internet Banking," in The proceedings of The International Seminar, IndonesiaMalaysia, The role of Harmonization of Economics and Business Discipline in Global Competitiveness, Banda Aceh, 2002, pp. 14-15.

[16] V. L. Saga and R. W. Zmud, "The Nature and Determinants of IT Acceptance, Routinization and Infusion," in The IFIP TC8 Working conference of Diffusion, Transfer and Implementation of Information Technology, North Holland, 1994.

[17] Ritu Agarwal and Elena Karahanna, "Time Flies when you're having fun: Cognitive arsorption and beliefs about information technology usage," MIS Quarterly, pp. 665-694, 2000.

[18] Su-Houn Liu, Hsiu-Li Liao, and ChengJun Peng, "Applying the technology acceptance model and flow theory to online e-learning users acceptance behaviour," Issues in Infomation Systems, pp. 175-181, 2005.

[19] Alexander Serenko, Nick Bontis, and Brian Detlor, "End-user adoption of animated interface agents on everyday work applications," Behaviour \& Information Technology, Vol. 26, pp. 119-132, 2007.

[20] J. Gleadle, At a Glance Anamnesis dan Pemeriksaan Fisik. Jakarta: Erlangga, 2007.

[21] V., \& Davis, F. D. Venkatesh, "A theoritical extension of the technology acceptance model: Four longitudinal field studies," Management Science Vol. 62, No. 2, pp. 186-204, 2000. 
[22] Abdullah Habibi, Naneng Setiasih, and Jensi Sartin, "A Decade of Reef Check Monitoring: Indonesian Coral Reefs, Condition and Trends," The Indonesian Reef Check Network , 2007.

[23] G. Diansyah, T.Z. Ulqodry, M. Rasyid, and A. Djawanas, "The Measurements of Calcification Rates in Reef Corals Using Radioisotope $45 \mathrm{Ca}$ at Pongok Sea, South Bangka," Atom Indonesia, vol. Vol. 37 , pp. 11-16, December 2011.

[24] C Beall, B J Lawrence, V Ila, and F Dellaert, "Reconstruction 3D Underwater Structures," , Atlantic, 2010.

[25] V Brandou et al., "3D reconstruction of natural underwater scenes using the stereovision system iris," , Aberdeen, 2007.

[26] A Leone, G Diarco, and C Distante, "A Stereo Vision Framework for 3-D Underwater Mosaicking," 2008.

[27] K. Iqbal, R. A. Salam, A. Osman, and A. Z. Talib, "Underwater Image Enhancement Using an Integrated Colour Model," IAENG International Journal of Computer Science, Vol. 34, No. 2, 2007.

[28] J Floor Anthoni. (2005) [Online]. http://www.seafriends.org.nz/phgraph/wa ter.htm

[29] K. Iqbal, M. Odetayo, A. James, and R. Abdul Salam, "Enhancing The Low Quality Images Using Unsupervised Colour Correction Method," in IEEE International Conference on Systems Man and Cybernetics (SMC), 2010.

[30] P. Subashini, M. M. Kumar, S. K. Thakur, and G. Padmavathi, "Comparison of Filters used for Underwater Image Pre-Processing," International Journal of Computer Science and Network Security, vol. 10, no. 1, pp. 58-65, 2010.
[31] Andrew Hogue, Andrew German, and Michael Jenkin, "Underwater environment reconstruction using stereo and inertial data," in IEEE International Conference on Systems, Man and Cybernetics, 2007.

[32] Rajesh Garg, Bhawna Mittal, and Sheetal Garg, "Histogram Equalization Techniques For Image Enhancement," IJECT, vol. 2, no. 1, 2011.

[33] Puran Gour, Balvant Singh Rajesh Kumar Rai, "Underwater Image Segmentation using CLAHE Enhancement and Thresholding," International Journal of Emerging Technology and Advanced Engineering, vol. 2, no. 1, January 2012.

[34] B. Singh, R. S. Mishra, and P. Gour, "Analysis of Contrast Enhancement Techniques For Underwater Image," International Journal of Computer Technology and Electronics Engineering, pp. pp. 190-194., Vol. 1, Issue 2, October 2011.

[35] Prabhakar C J and Praveen Kumar P U, "3D Surface Reconstruction of Underwater Objects," International Journal of Computer Applications, pp. 31-37, April 2012.

[36] A. Mahiddine, J. Seinturier, J. M. Boï, and P. Drap D. Merad, "Performances Analysis of Underwater Image Preprocessing Techniques on the Repeatability of SIFT and SURF Descriptors," in WSCG 2012: 20th International Conference on Computer Graphics, Visualization and Computer Vision, 2012.

[37] Pulung Nurtantio Andono, I Ketut Eddy Purnama, and Mochamad Hariadi, "Underwater Image Enhancement Using Adaptive Filtering For Enhanced SiftBased Image Matching," Journal of Theoretical and Applied Information Technology, vol. 51, no. 3, pp. 392-399, 
May 2013.

[38] Suprijanto, Gianto, E. Juliastuti, Azhari, and Lusi Epsilawati, "Image Contrast Enhancement for Film-Based Dental Panoramic Radiography," in International Conference on System Engineering and Technology, 2012.

[39] David G Lowe, Distinctive Image Featuresfrom Scale-Invariant Keypoints.: International Journal of Computer Vision, 2004.

[40] Øyvind Hjelle and Morten Dæhlen, Triangulations and Applications. Berlin Heidelberg: Springer, 2006.

[41] P.N. Andono, E.M. Yuniarno, M. Hariadi, and V. Venus, "3D reconstruction of under water coral reef images using low cost multi-view cameras," in International Conference on Multimedia Computing and Systems (ICMCS), Tangier, Maroko, 2012, pp. $803-808$.

[42] A. Levin, D. Lischinski, and Y. Weiss, "A Closed-Form Solution to Natural Image Matting," IEEE Transactions on Pattern Analysis And Machine Intelligence, vol. 30, pp. 1-15, February 2008.

[43] T. Porter and T. Duff, "Compositing digital images," Computer Graphics, vol. $18,1984$.

[44] A. Levin, A. Rav-Acha, and D. Lischinski, "Spectral matting," IEEE Transactions on Pattern Analysis and Machine Intelligence, vol. 30, 2008.

[45] K. Lang, "Fixing Two Weaknesses of the Spectral Method," in Proc. Advances in Neural Information Processing Systems, 2005.

[46] S.X. Yu and J. Shi, "Multiclass Spectral Clustering," in Proc. Int'lConf. Computer Vision, 2003.
[47] L. Zelnik-Manor and P. Perona, "SelfTuning Spectral Clustering," in Proc. Advances in Neural Information Processing Systems, 2005.

[48] A. Ng, M. Jordan, and Y. Weiss, "Spectral Clustering: Analysis and an Algorithm," in Proc. Advances in Neural Information Processing Systems, 2001.

[49] D. Tolliver and G. Miller, "Graph Partitioning by Spectral Rounding: Applications in Image Segmentation and Clustering," in Proc. IEEE Int'l Conf. Computer Vision and Pattern Recognition, 2006.

[50] T.J. Roos, Fuzzy Logic With Engineering Applications, Third Edition.: John Wiley \& Sons, 2010.

[51] W.B. Pennebaker and J.L. Mitchell, JPEG - Still Image Data Compression Standard. Newyork: International Thomsan Publishing, 1993.

[52] R. Suko Basuki, Moch. Hariadi., and R.A. Pramunendar, "Fuzzy C-Means Algorithm for Adaptive Threshold on Alpha Matting," in Proc of Computer Society Coference on Information Technology and Electrical Engineering, Yogyakarta, Indonesia, 2012.

[53] C. Mythili and V. Kavitha, "Color Image Segmentation using ERKFCM," International Journal of Computer Applications, vol. Vol. 41, 2012. 